\title{
INVENTÁRIO DAS ARANHAS ARBORÍCOLAS DE TRÊS REGIÕES DE SANTA MARIA, RS, BRASIL
}

Leocádia F. Indrusiak e Carla B. Kotzian

Departamento de Biologia - CCNE

UFSM - Santa Maria, RS

\section{RESUMO}

Relata-se o resultado de coletas sazonais de aranhas arborícolas realizadas nos anos de 1995 e 1996, nas localidades de Perau Velho, Cidade dos Meninos e São Marcos, nos arredores de Santa Maria, RS. Foram capturados 2381 espécimes, distribuídos em 20 famílias e 65 gêneros. Apresenta-se também uma lista preliminar de espécies.

\section{ABSTRACT}

This study describes the results of seasonal collects of arboreal spiders during the years of 1995 and 1996 in Perau Velho, Cidade dos Meninos and São Marcos, in the outskirts of Santa Maria city in Rio Grande do Sul state. They were captured 2381 specimens distributed in 20 families and 65 genera. It is also presented a preliminary list of species. 


\section{INTRODUÇÃO}

As revisões de MELLO-LEITÃO (1943) e BÜCHERL (1952) sobre as aranhas do Rio Grande do Sul não mencionaram a área de Santa Maria de modo particular. A única investigação a dedicar-se particularmente à araneofauna local foi realizada em 1982. Trata-se de um levantamento efetuado por uma equipe de pesquisadores da Fundação Zoobotânica do Rio Grande do Sul que prospectou uma área que, mais tarde, se tornaria a Reserva Biológica da Barragem Saturnino de Brito (CORSAN), junto ao Rio Ibicuí Mirim. Entretanto, o relatório produzido na época foi de circulação restrita, e por não ter sido publicado torna muito difícil o acesso aos resultados. É provável que o material então obtido tenha sido citado de forma esparsa em revisões sistemáticas realizadas posteriormente, como as de BRESCOVIT (1992 a e b, 1996), BONALDO \& BRESCOVIT (1992) e LISE \& BRAUL Jr. (1995), pois nelas foram feitas algumas citações de material de Santa Maria e arredores.

O presente estudo é parte de um projeto de levantamento da fauna araneológica da região de Santa Maria, iniciado pelas autoras em 1990, utilizando primeiramente material já depositado em coleção no Departamento de Biologia da Universidade Federal de Santa Maria (UFSM). Tal acervo é constituído por exemplares coletados para aulas práticas, por material proveniente de doações e pelo produto de uma campanha de coletas realizada em 1992 e 1993 em pontos determinados sobre 8 quadrantes de um mapa do município (Fig.1), os quais atenderam a fatores como tipo de vegetação e relevo, presença de corpos d'água e condições de acesso ao local.

Este material, parcialmente registrado em livro-tombo, indicava que as aranhas mais comuns na região eram as das famílias Theridiidae e Araneidae e que a maior abundância de formas ocorria na região dos morros da cidade. Entretanto, a falta de metodologia e de periodicidade das coletas não permitia confirmar estes resultados sobre diversidade e abundância; também não era possível estabelecer, por exemplo, épocas preferenciais 


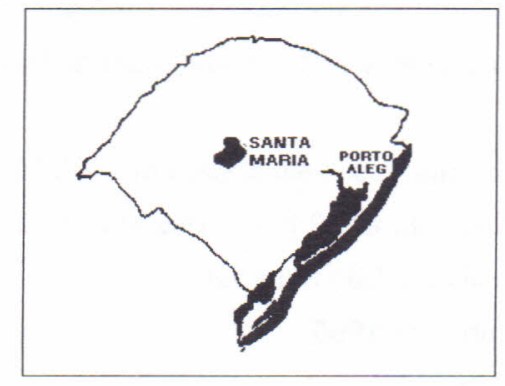

\section{MAPA DO MUNICIPIO DE \\ SANTA MARIA}

\section{CONYENCOOES USADAS}

Rodovia Federal

Rodovia Estadual

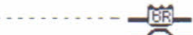

Estrada de Ferro ..........

Locais de coleta de amostragem

Área de Estudo ...............

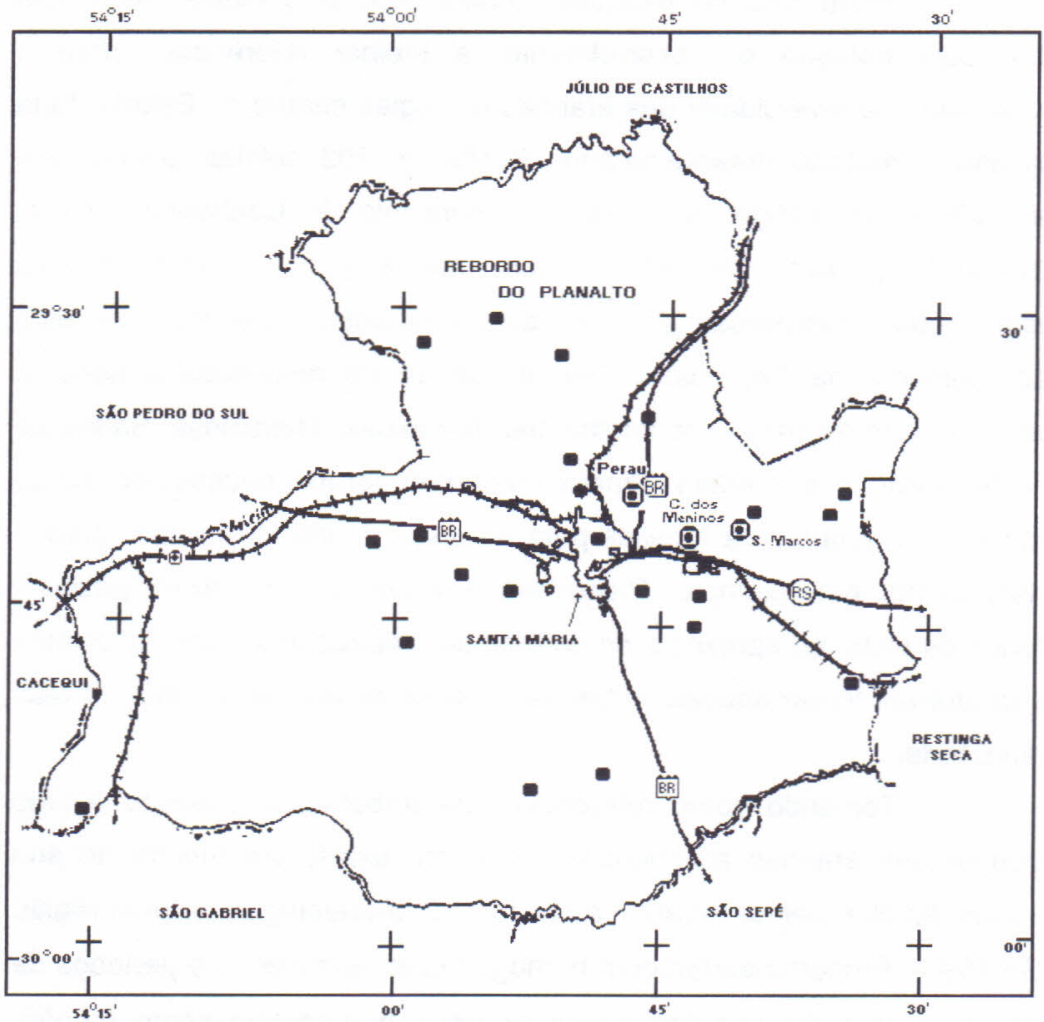

Figura 1 - Mapa da área de estudo

Rev. Ciência e Natura, Santa Maria, 20: 187 -2/4 , 1998. 
para a ocorrência de representantes de determinadas espécies, ou mesmo os momentos em que se obteria a maior representatividade quali-quantitativa de aranhas e suas formas adultas.

Visando sanar tais lacunas as autoras realizaram, em 1995/96, coletas sazonais, conforme relacionado a seguir, em 3 locais dos morros de Santa Maria (Perau Velho, Cidade dos Meninos e São Marcos):

Primavera - outubro e novembro de 1995

Verão - janeiro de 1995 e 1996

Outono - abril e maio de 1995, março, abril e maio de 1996 Inverno - agosto de 1995

Nesta fase da pesquisa conhecia-se já o estudo de BUSS (1993), cujo trabalho é, possivelmente, a melhor referência para o conhecimento da diversidade das aranhas da região central do Estado. Esta pesquisadora realizou, durante os anos de 1992 e 1993, coletas sazonais em matas-galerias de sangas e arroios no município de Cachoeira do Sul, relativamente próximo de Santa Maria (cerca de $100 \mathrm{~km}$ ), e com características paisagísticas e climáticas semelhantes, uma vez que está situado também na Depressão Central. Dentre os resultados obtidos, a autora citou, como famílias predominantes, Araneidae, Theridiidae, Salticidae e Anyphaenidae, nesta ordem; o maior número de formas adultas ocorreu de setembro a dezembro. Há famílias para as quais nunca foram encontrados adultos, como, por exemplo, Pisauridae, levando a crer numa possível mudança de nicho ao aproximar-se da fase de maturação sexual. As coletas mais produtivas foram aquelas feitas na periferia da galeria, exceto em dias de vento forte.

Tomando como referência este trabalho, o presente estudo centrou-se nas aranhas arborícolas por serem estas, em função de sua variedade, as que melhor retratam a diversidade araneológica de uma região (BUSS,1993). Procurou-se também homogeneizar os métodos e períodos de coleta, de forma a obter-se dados mais precisos, que confirmassem, ou não, as observações anteriores sobre grupos predominantes e épocas de 190 Rev. Ciência e Natura, Santa Maria, 20: 187 -214 , 1998. 
recrutamento, de modo a que os resultados pudessem ser comparados com aqueles obtidos por Buss.

\section{2. ÁREA ESTUDADA}

A área estudada (Fig. 1) está situada no Rebordo do Planalto, uma das unidades de relêvo descritas por PEREIRA et al. (1989) para a região de Santa Maria, e foi escolhida em função das observações anteriores, que davam como mais rica em formas de aranhas a região dos morros da cidade. Em termos de vegetação, esta área pertence à Floresta Estacional Decidual da Fralda da Serra Geral, com composição florística bastante heterogênea (BEARZI et al., 1992). Nos 3 locais de coleta, São Marcos, Cidade dos Meninos e Perau Velho, a mata se encontra bastante modificada e danificada pela vizinhança de minifúndios agrícolas e pela presença de gado (MACHADO \& LONGHI, 1990).

Apesar de próximos, os locais de coleta apresentam algumas diferenças.

Em São Marcos, as coletas foram feitas principalmente em um mato de encosta, bastante exposto ao sol e ao vento, com árvores de grande porte e, com exceção de uma faixa de 2 a 3 metros da borda do mato, quase sem vegetação rasteira, provavelmente em função da presença de gado. Nas clareiras aparecem alguns arbustos e cipós, estes últimos reduzidos a emaranhados de galhos quase sem folhas. A encosta é parcialmente marginada por uma pequena sanga, cujo leito, na época do trabalho, esteve sempre seco, mas que mostrava, na vegetação rasteira, vestígios de enxurradas. Neste local, observou-se, entre outras espécies arbóreas, as seguintes: angico-vermelho (Parapiptadenia rigida), canela-branca (Aiouea saligna), vacum (Allophyllus guaranyticus), guajuvira (Patagonula americana ), mamica-de-cadela (Zoanthoxillum rhoifolium ), maria-mole (Pisonia ambigua ), guabijú (Myrcianthes pungens), araçá-do-mato (Psidium cattleyanum), garupá (Alloysia selowi). Entre a vegetação de menor porte 
observou-se unha-de-gato (Acacia bonariensis), chá-de-bugre (Casearia sylvestris), imbira (Daphnopsis racemosa), sucará (Dasiphillum spinescens), mata-pasto (Vernonia sp.), fel-da-terra (Hybanthus bigibbosus), quatroquinas (Hystia mutabilis), erva-lanceta (Solidago chilensis), erva-de-bicho (Polygonum hydropiperoides), japecanga (Smilax sp.), cipó-jarrinha (Aristolochia triangularis), dentre outras.

$\mathrm{Na}$ Cidade dos Meninos, o local amostrado foi uma trilha de contorno de um morro (Morro da Via - sacra), coletando-se desde o nível do chão até cerca de 1 ou 2 metros de altura da encosta. É um local bastante ensolarado, mas abrigado do vento pela própria encosta, de um lado, e, do outro, pela mata-galeria de um pequeno arroio. A largura da trilha varia, desde uma estreita senda, recoberta pelas árvores, até uma espécie de clareira, bastante larga, marginada por vegetação de menor porte. Esta trilha dá acesso ao Morro do Elefante, cuja composição florística foi estudada por MACHADO \& LONGHI (1990). Segundo estes autores as árvores mais características e importantes são: canela-preta (Nectandra megapotamica), catiguá-vermelho (Trichilia clausseni), camboatá-vermelho (Cupania vernalis), timbaúva (Enterolobium contortisiliquum), tanheiro (Alchornea triplinervia), pessegueiro-do-mato (Prunus subcoriacea) e chal-chal (Allophyllus edulis . Observou-se também açoita-cavalo (Luehea divaricata), tarumã (Vitex sp.) e, entre outras plantas de menor porte, unha-de-gato (Acacia bonariensis), chá-de-bugre (Casearia sylvestris), sucará (Dasiphillum spinescens), fel-da-terra (Hybanthus bigibbosus), urtigão-manso (Boheravia caudata), além de vários Citrus (laranjeiras, bergamoteiras e limoeiros).

O Perau Velho é um trecho de estrada com forte declive (Estrada Velha do Pinhal), localizado na encosta da Serra do Pinhal, ramo local da Serra Geral. Também aqui a vegetação de pequeno porte, onde foram feitas preferencialmente as coletas, é bastante protegida do sol e do vento pela própria encosta e pelo mato marginal da estrada. Esta área fica muito próxima ao Morro das Três Marias, cuja estrutura fitossociológica foi analisada por BEARZI et al. (1992), os quais consideraram, como mais 
características e importantes, as seguintes espécies arbóreas: canela-deveado (Helietta longifoliata), camboatá-vermelho ( $C$. vernalis), açoita-cavalo (L. divaricata), cabriúva (Myrocarpus frondosus), canela-preta ( $N$. megapotamica), angico-vermelho ( $P$. rigida) e guajuvira ( $P$. americana). Observou-se também a presença de vacum (Allophyllus guaranyticus), esporão-de-galo (Acnistus breviflorus), aroeira-periquita (Schinus molle), urtigão-manso (B. caudata), bem como ervas ( $H$. bigibbosus, Verbascum sp., Piper sp.) e cipós (Aristolochia sp., Smilax sp.).

\section{MATERIAL E MÉTODOS}

Foram utilizados, tanto quanto possível, a metodologia e os materiais relatados por BUSS (1993), isto é: fez-se coletas generalistas pela manhã, utilizando-se um guarda-chuva entomológico medindo $1 \mathrm{mX1m}$, fazendo-se 5 a 10 acionamentos. Em alguns locais, foi possível coletar manualmente as aranhas, localizadas visualmente, diretamente das teias ou dos refúgios. Os exemplares obtidos foram colocados em álcool $70 \%$ e triados no laboratório.

As amostragens foram feitas sobre toda a comunidade marginal do mato (árvores, arbustos, cipós e plantas herbáceas com mais de $40 \mathrm{~cm}$ de altura), distanciando-se da borda para o interior cerca de 2 a 5 metros e alcançando cerca de $2 \mathrm{~m}$ de altura; não foi possível coletar nas copas das árvores em virtude da sua grande altura. No interior do mato, coletou-se na vegetação das clareiras e nos emaranhados de cipós que pendiam das copas. Na Cidade dos Meninos, coletou-se na vegetação que pende sobre o arroio e, em São Marcos, na vegetação marginal do leito seco de sanga. No Perau Velho, foi possível obter material da copa de algumas árvores e arvoretas cujos ramos pendiam sobre a estrada e um local utilizado como estacionamento para automóveis. 
Quanto à época, as campanhas cumpriram um programa de coletas sazonais, mantendo aproximadamente os mesmos pontos determinados na $1^{\underline{a}}$ busca. Em alguns locais as coletas foram repetidas, na tentativa de obter-se as formas adultas de algumas das espécies coletadas. As coletas foram realizadas nas seguintes datas:

\begin{tabular}{llllll}
\multicolumn{2}{c}{ Perau Velho } & \multicolumn{2}{c}{ São Marcos } & \multicolumn{2}{c}{ Cid. dos Meninos } \\
$19 .{ }^{1} .95$ & (Verão) & 24.1 .95 & (Verão I) & 17.1 .95 & (Verão I) \\
22.8 .95 & (Inverno) & 18.4 .95 & (Outono I) & 17.5 .95 & (Outono) \\
20.10 .95 & (Primavera) & 28.8 .95 & (Inverno) & 25.8 .95 & (Inverno) \\
21.3 .96 & (Outono I) & 24.11 .95 & (Primavera) & 7.11 .95 & (Primavera) \\
22.5 .96 & (Outono II) & 10.1 .96 & (Verão II) & 22.1 .96 & (Verão II) \\
& & 17.4 .96 & (Outono II) & &
\end{tabular}

Para a determinação das famílias foi usada a chave de identificação de PIKELIN \& SCHIAPELLI (1963); alguns dos gêneros foram determinados com base em KASTON \& KASTON (1953) e LEVI \& LEVI (1962, 1990). Muitos espécimes foram identificados com a colaboração de pesquisadores de outras instituições, notadamente do Laboratório de Aracnologia da Pontifícia Universidade Católica do Rio Grande do Sul (PUC/RS) e Laboratório de Artrópodes do Instituto Butantan (IBSP). Mesmo tendo-se contado com a colaboração dos especialistas supra-citados, os dados apresentados a nível de gênero ou espécie são considerados parciais devido, principalmente, a dois motivos: a) há poucas revisões sistemáticas sobre a araneofauna da região Neotropical; b) durante as coletas obteve-se um pequeno número de formas adultas (cerca de $30 \%$ do total de exemplares), sendo que em alguns grupos só foram obtidos indivíduos jovens e sub-adultos; este último fato impossibilitou que a identidade genérica ou específica de muitos exemplares fosse determinada. Assim sendo, e para que os indivíduos imaturos pudessem ser incluídos no 
presente estudo, a maioria dos dados quali-quantitativos é aqui discutida a nível de família.

O material coletado encontra-se depositado na coleção de aranhas da UFSM, com exceção de alguns lotes, cedidos para estudo ao Laboratório de Aracnologia da PUC/RS e ao Laboratório de Artrópodes Peçonhentos do IBSP.

\section{RESULTADOS E DISCUSSÃO}

A tab 1 e fig. 2 mostram os resultados obtidos em termos de abundância (número total de indivíduos) e de diversidade (famílias) nos três pontos de coleta.

Foram coletados espécimes de 19 famílias (tab.1). Destas, pode-se verificar que Araneidae domina a amostragem, com 539 indivíduos, principalmente em virtude de sua abundância no Perau Velho. A segunda família em número é Theridiidae, predominante em São Marcos e Cidade dos Meninos (454 indivíduos). Seguem-se as famílias Anyphaenidae (391 exemplares), Thomisidae (277 exemplares) e Salticidae (264 exemplares). A predominância de Araneidae e Theridiidae era, de certa forma, esperada, pois estes são os grupos melhor representados numericamente na coleção da UFSM, compreendendo respectivamente 262 e 241 lotes de um total de 1383 (ou seja, cerca de $37 \%$ ). Por essa mesma razão supõe-se que também em termos de diversidade esta coleção seja representativa da área em estudo.

Ainda quanto à abundância, estes resultados são corroborados por aqueles obtidos por BUSS (1993) para Cachoeira do Sul. Naquela região, estas famílias também são as melhor representadas numericamente, embora Salticidae seja mais abundante que Anyphaenidae. 


\begin{tabular}{|c|c|c|c|c|c|c|}
\cline { 2 - 8 } \multicolumn{1}{c|}{} & \multicolumn{7}{c|}{ Perau Velho } \\
\hline Familias & 19. & 22. & 20. & 21. & 22. & \\
1 & 8 & 10 & 3 & 5 & Tot. \\
\hline Anyphaenidae & 11 & 50 & 39 & 11 & 19 & 130 \\
\hline Araneidae & 33 & 58 & 49 & 80 & 57 & 277 \\
\hline Clubionidae & 11 & 1 & 0 & 2 & 0 & 14 \\
\hline Corinnidae & 2 & 0 & 1 & 0 & 1 & 4 \\
\hline Deinopidae & 0 & 0 & 0 & 0 & 0 & 0 \\
\hline Dictynidae & 0 & 0 & 0 & 0 & 1 & 1 \\
\hline Hersiliidae & 0 & 0 & 0 & 0 & 0 & 0 \\
\hline Heteropodidae & 1 & 1 & 3 & 1 & 2 & 8 \\
\hline Linyphiidae & 0 & 3 & 1 & 0 & 1 & 5 \\
\hline Mimetidae & 0 & 3 & 6 & 1 & 0 & 10 \\
\hline Oxyopidae & 1 & 3 & 3 & 1 & 1 & 9 \\
\hline Philodromidae & 1 & 5 & 3 & 5 & 4 & 18 \\
\hline Pholcidae & 0 & 0 & 0 & 0 & 0 & 0 \\
\hline Pisauridae & 0 & 1 & 0 & 0 & 0 & 1 \\
\hline Salticidae & 4 & 34 & 16 & 5 & 13 & 72 \\
\hline Senoculidae & 0 & 2 & 0 & 0 & 0 & 2 \\
\hline Tetragnathidae & 14 & 8 & 10 & 8 & 2 & 42 \\
\hline Theridiidae & 18 & 50 & 34 & 26 & 17 & 145 \\
\hline Thomisidae & 4 & 16 & 17 & 7 & 7 & 51 \\
\hline Uloboridae & 0 & 5 & 0 & 0 & 0 & 5 \\
\hline Total & 100 & 240 & 182 & 147 & 125 & 794 \\
\hline
\end{tabular}

Tabela 1 - Quantidade total de aranhas obtidas nos diferentes pontos de coleta (Perau Velho) 


\begin{tabular}{|c|c|c|c|c|c|c|}
\cline { 2 - 8 } \multicolumn{1}{c}{} & \multicolumn{7}{c|}{ Cidade dos Meninos } \\
\hline Familias & 17. & 17. & 25. & 7. & 22 & Tot. \\
& 1 & 5 & 8 & 11 & 1 & \\
\hline Anyphaenidae & 23 & 18 & 42 & 17 & 12 & 112 \\
\hline Araneidae & 19 & 19 & 33 & 9 & 12 & 92 \\
\hline Clubionidae & 0 & 0 & 2 & 0 & 0 & 2 \\
\hline Corinnidae & 1 & 0 & 0 & 0 & 3 & 4 \\
\hline Deinopidae & 1 & 0 & 0 & 0 & 0 & 1 \\
\hline Dictynidae & 0 & 0 & 0 & 0 & 3 & 3 \\
\hline Hersiliidae & 0 & 0 & 1 & 0 & 0 & 1 \\
\hline Heteropodidae & 1 & 0 & 0 & 1 & 0 & 2 \\
\hline Linyphiidae & 4 & 3 & 8 & 5 & 10 & 30 \\
\hline Mimetidae & 0 & 0 & 7 & 1 & 1 & 9 \\
\hline Oxyopidae & 0 & 0 & 0 & 1 & 0 & 1 \\
\hline Philodromidae & 0 & 0 & 2 & 3 & 3 & 8 \\
\hline Pholcidae & 0 & 0 & 0 & 1 & 0 & 1 \\
\hline Pisauridae & 3 & 3 & 5 & 4 & 0 & 15 \\
\hline Salticidae & 12 & 12 & 31 & 5 & 13 & 73 \\
\hline Senoculidae & 0 & 1 & 1 & 0 & 0 & 2 \\
\hline Tetragnathidae & 9 & 15 & 20 & 20 & 24 & 88 \\
\hline Theridiidae & 25 & 51 & 25 & 10 & 20 & 131 \\
\hline Thomisidae & 0 & 9 & 31 & 15 & 38 & 93 \\
\hline Uloboridae & 0 & 0 & 1 & 0 & 1 & 2 \\
\hline Total & 98 & 131 & 209 & 92 & 140 & 670 \\
\hline
\end{tabular}

Tabela 1 - Continuação (Cidade dos meninos) 


\begin{tabular}{|c|c|c|c|c|c|c|c|c|}
\cline { 2 - 8 } \multicolumn{1}{c|}{} & \multicolumn{7}{c|}{ São Marcos } & \multicolumn{1}{l}{} \\
\hline & 24 & 18. & 28. & 24 & 10 & 17. & Tot & Tot. \\
Familia & 1 & 4 & 8 & 11 & 1 & 4 & & Ger. \\
\hline Anyphaenidae & 4 & 36 & 55 & 18 & 3 & 33 & 149 & 391 \\
\hline Araneidae & 12 & 31 & 52 & 36 & 12 & 27 & 170 & 539 \\
\hline Clubionidae & 0 & 2 & 3 & 2 & 0 & 1 & 8 & 24 \\
\hline Corrinidae & 0 & 0 & 1 & 0 & 4 & 1 & 6 & 14 \\
\hline Deinopidae & 0 & 0 & 1 & 0 & 0 & 1 & 2 & 3 \\
\hline Dictynidae & 0 & 0 & 0 & 0 & 0 & 0 & 0 & 4 \\
\hline Hersiliidae & 0 & 0 & 0 & 0 & 0 & 0 & 0 & 1 \\
\hline Heteropodidae & 0 & 0 & 0 & 0 & 2 & 3 & 5 & 15 \\
\hline Linyphiidae & 0 & 5 & 8 & 4 & 2 & 3 & 22 & 57 \\
\hline Mimetidae & 2 & 1 & 1 & 1 & 3 & 1 & 9 & 28 \\
\hline Oxyopidae & 0 & 0 & 0 & 0 & 0 & 0 & 0 & 10 \\
\hline Philodromidae & 1 & 1 & 2 & 2 & 2 & 1 & 9 & 35 \\
\hline Pholcidae & 0 & 0 & 0 & 0 & 2 & 2 & 4 & 5 \\
\hline Pisauridae & 1 & 2 & 5 & 1 & 1 & 6 & 16 & 32 \\
\hline Salticidae & 8 & 12 & 36 & 17 & 18 & 28 & 119 & 264 \\
\hline Senoculidae & 0 & 0 & 2 & 0 & 1 & 0 & 3 & 7 \\
\hline Tetragnathidae & 5 & 4 & 17 & 14 & 11 & 28 & 79 & 209 \\
\hline Theridiidae & 11 & 30 & 33 & 27 & 13 & 64 & 178 & 454 \\
\hline Thomisidae & 12 & 16 & 38 & 26 & 29 & 12 & 133 & 277 \\
\hline Uloboridae & 0 & 0 & 5 & 0 & 0 & & 5 & 12 \\
\hline Total & 56 & 140 & 259 & 148 & 103 & 211 & 917 & 2381 \\
\hline
\end{tabular}

Tabela 1 - Continuação (São Marcos) 


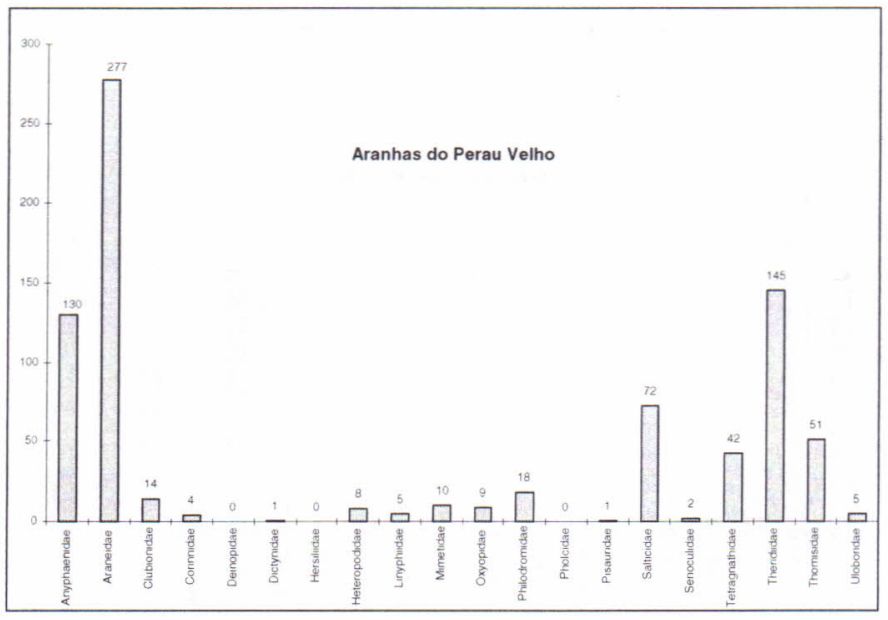

Figura 2a - Distribuição das famílias nos pontos de coleta (Perau Velho)

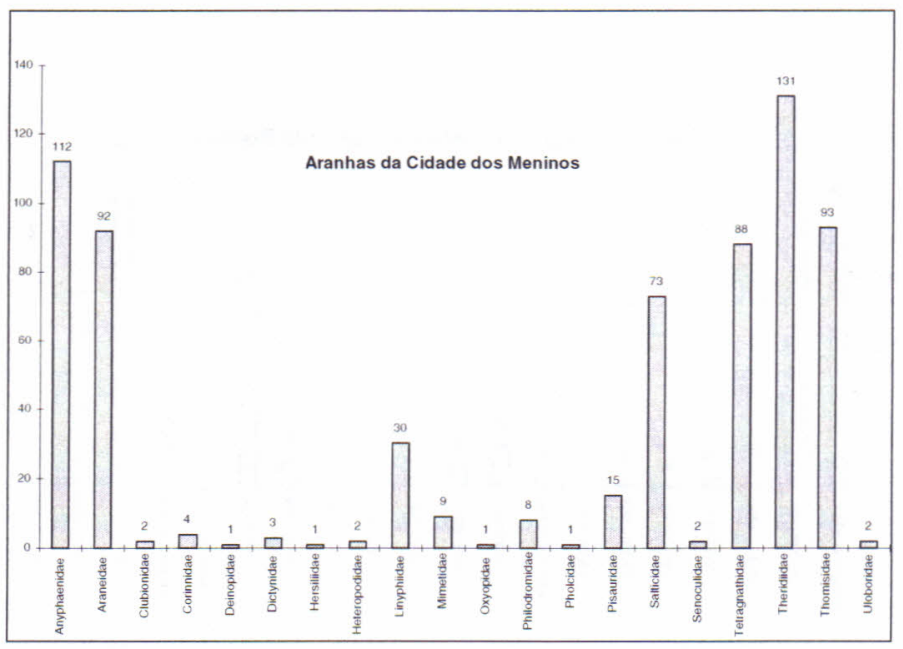

Figura 2b - Continuação (Cidade dos Meninos) 


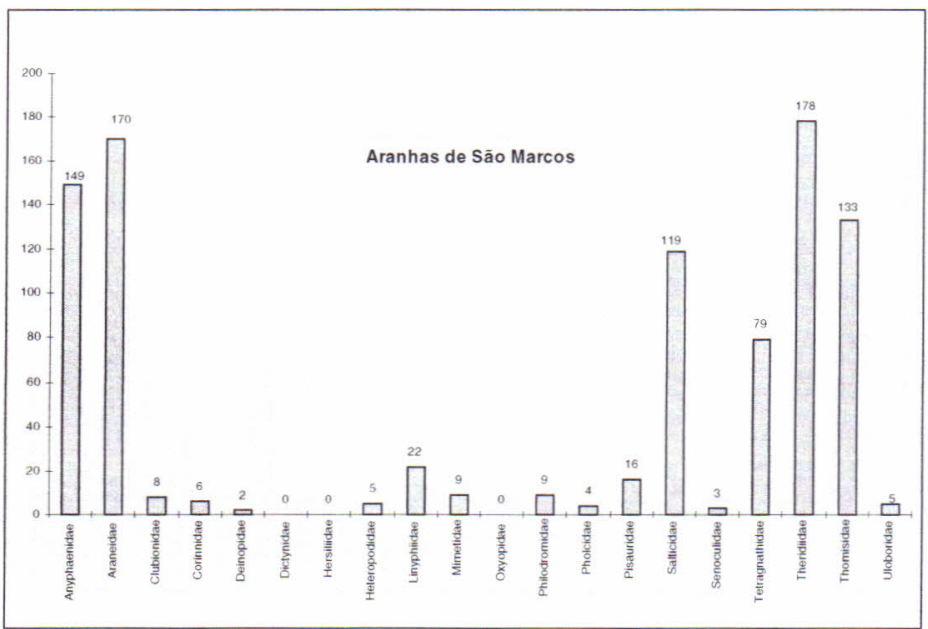

Figura 2c - Continuação (São Marcos)

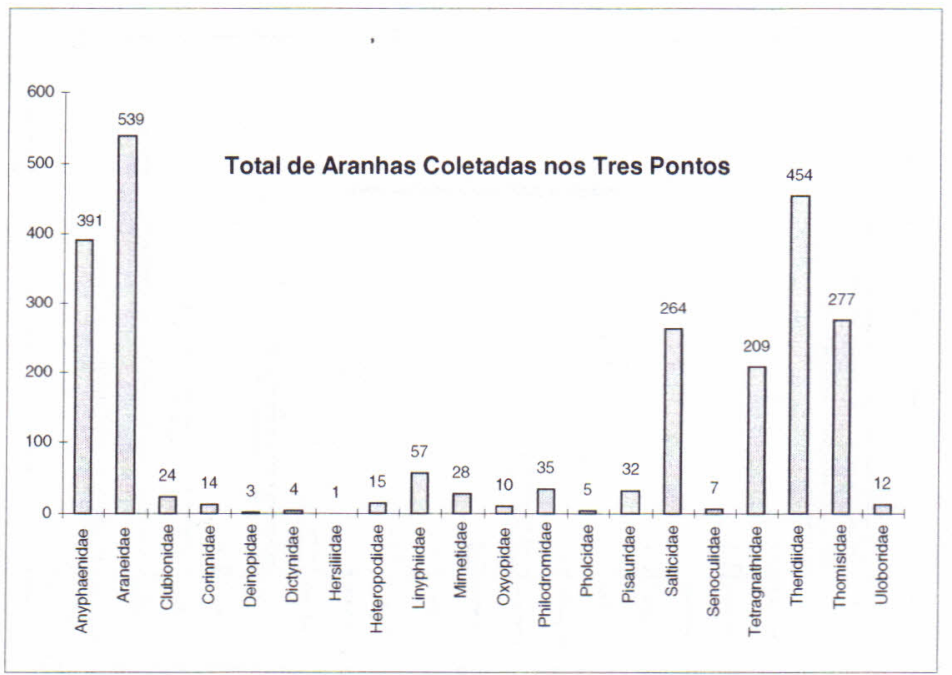

Figura 2d - Continuação (Total de aranhas nos três pontos) 
A tab. 1 fig. 2 mostram também que a maioria das aranhas coletadas está presente, simultaneamente, nos três pontos de coleta (15 das 20 famílias encontradas) ou pelo menos em dois deles (4 das famílias); apenas da família Hersiliidae aparecem representantes em um único local, Cidade dos Meninos.

A semelhança quanto às famílias, registrada nos três locais estudados, parece confirmar que a composição taxonômica observada representa, com razoável fidelidade, a diversidade das aranhas arborícolas dos morros da região, pelo menos no que concerne aos grupos que podem ser coletados com a metodologia empregada.

A tab. 2 demonstra os resultados obtidos a nivel de gênero ou espécie.

Os gêneros representados por um maior número de indivíduos nas amostragens são: Araneus (152), Tmarus (121), Aysha (86), Argyrodes (83), Nephila (74), Misumenops (70), Metepeira (69), Micrathena (55), Achaearanea e Eustala (51). O status de alguns deles, no entanto, ainda não se encontra perfeitamente delimitado, como é o caso, por exemplo, de Misumenops e outros Thomisidae (Buss, comunicação pessoal). Portanto, a abundância aqui assinalada não é conclusiva.

Poucas aranhas foram identificadas a nivel de espécie. Dentre estas, a mais abundante é Araneus unanimus (Keyserling, 1880) representada por 80 exemplares, seguindo-se Nephila clavipes (L., 1758), com 74 exemplares coletados; entretanto, se os gêneros Tmarus e Argyrodes estiverem representados, cada um, por uma única espécie, essas seriam as mais abundantes. Contudo, deve-se ressalvar que vários exemplares de $N$. clavipes e Argyrodes sp. (esses últimos capturados, em sua grande maioria, em teias associadas às da primeira espécie) foram coletados manualmente, já que suas teias são bastante visíveis. Considerase, assim, que este resultado possa ser tendencioso. $O$ mesmo pode, também, ter ocorrido com certos Araneidae, cujo tamanho das teias e/ou indivíduos, em relação às outras famílias pode ter facilitado a captrura 


\begin{tabular}{|c|c|c|c|}
\hline ESPÉCIES & S. MARCOS & P. VELHO & C. DOS MENINOS \\
\hline \multicolumn{4}{|l|}{ ARANEIDAE } \\
\hline \multicolumn{4}{|l|}{ Acacesia } \\
\hline Acacesia sp. & 2 & 1 & - \\
\hline \multicolumn{4}{|l|}{ Alpaida } \\
\hline A. bicornuta & 1 & - & - \\
\hline A. lomba & 1 & - & 1 \\
\hline A. nonoai & - & 4 & 2 \\
\hline Alpaida spp. & 2 & 4 & 4 \\
\hline \multicolumn{4}{|l|}{ Araneus } \\
\hline A. lathirinus & 2 & - & - \\
\hline A. unanimus & 26 & 49 & 5 \\
\hline Araneus spp. & 17 & 49 & 4 \\
\hline \multicolumn{4}{|l|}{ Argiope } \\
\hline Argiope argentata & - & 2 & 1 \\
\hline \multicolumn{4}{|l|}{ Cyclosa } \\
\hline Cyclosa spp. & 4 & - & 2 \\
\hline \multicolumn{4}{|l|}{ Eustala } \\
\hline Eustala spp. & 10 & 27 & 14 \\
\hline \multicolumn{4}{|l|}{ Gastheracantha } \\
\hline G, cancriformis & 13 & 5 & 5 \\
\hline \multicolumn{4}{|l|}{ Larinia } \\
\hline Larinia sp. & 4 & 1 & 1 \\
\hline \multicolumn{4}{|l|}{ Mangora } \\
\hline Mangora spp. & 9 & 17 & 3 \\
\hline \multicolumn{4}{|l|}{ Mecynogea } \\
\hline Mecynogea sp. & 1 & - & 3 \\
\hline \multicolumn{4}{|l|}{ Metepeira } \\
\hline Metepeira sp. & 19 & 50 & - \\
\hline \multicolumn{4}{|l|}{ Micrathena } \\
\hline Micrathena sp. & 1 & 14 & 1 \\
\hline M. lata & - & - & 4 \\
\hline M. rubicunda & 8 & 19 & 8 \\
\hline \multicolumn{4}{|l|}{ Ocrepeira } \\
\hline Ocrepeira sp. & - & 1 & 2 \\
\hline \multicolumn{4}{|l|}{ Parawixia } \\
\hline Parawixia spp. & 11 & 2 & 2 \\
\hline P. audax & 15 & 13 & 7 \\
\hline
\end{tabular}

Tabela 2 - Distribuição e abundância, por local, de algumas espécies identificadas

202 Rev. Ciência e Natura, Santa Maria, 20: $187-214$, 1998. 


\begin{tabular}{|c|c|c|c|}
\hline Scoloderus & & & \\
\hline Scoloderus sp. & - & - & 5 \\
\hline \multicolumn{4}{|l|}{ Verrucosa } \\
\hline V. meridionalis & 7 & - & 8 \\
\hline V. undecinvariolata & - & - & 1 \\
\hline \multicolumn{4}{|l|}{ THERIDIIDAE } \\
\hline \multicolumn{4}{|l|}{ Achaearanea } \\
\hline Achaearanea sp. & 36 & 7 & 8 \\
\hline \multicolumn{4}{|l|}{ Anelosimus } \\
\hline A. studiosus & 18 & 1 & 1 \\
\hline Anelosimus sp. & 6 & 2 & 1 \\
\hline \multicolumn{4}{|l|}{ Argyrodes } \\
\hline Argyrodes sp. & 11 & 17 & 55 \\
\hline \multicolumn{4}{|l|}{ Chrysso } \\
\hline Chrysso spp. & 19 & 7 & 6 \\
\hline \multicolumn{4}{|l|}{ Craspedisia } \\
\hline C. cornuta & 1 & - & - \\
\hline \multicolumn{4}{|l|}{ Episinus } \\
\hline Episinus sp. & - & 1 & 3 \\
\hline \multicolumn{4}{|l|}{ Euryopis } \\
\hline Euryopis sp. & 9 & 15 & 2 \\
\hline \multicolumn{4}{|l|}{ Hetschkia } \\
\hline Hetschkia sp. & - & 1 & 10 \\
\hline \multicolumn{4}{|l|}{ Phoroncidia } \\
\hline P. reimoseri & - & 4 & - \\
\hline \multicolumn{4}{|l|}{ Spintharus } \\
\hline S. flavidus & 3 & - & 3 \\
\hline \multicolumn{4}{|l|}{ Theridion } \\
\hline T. positivum & 13 & 2 & 7 \\
\hline Theridion $\mathrm{sp}$. & 5 & - & 1 \\
\hline \multicolumn{4}{|l|}{ Thwaitesia } \\
\hline Thwaitesia sp. & - & 38 & 5 \\
\hline \multicolumn{4}{|l|}{ ANYPHAENIDAE } \\
\hline \multicolumn{4}{|l|}{ Anyphaenoides } \\
\hline A. clavipes & 14 & 3 & 14 \\
\hline \multicolumn{4}{|l|}{ Aysha } \\
\hline Aysha spp. & 6 & 3 & - \\
\hline A. ericae & 5 & 10 & 6 \\
\hline
\end{tabular}

Tabela 2 - (continuação) 


\begin{tabular}{|c|c|c|c|}
\hline A. triunfo & 13 & 32 & 10 \\
\hline A. zenzesi & - & 1 & - \\
\hline \multicolumn{4}{|l|}{ Gayenna } \\
\hline G. maculatipes & 10 & 10 & 1 \\
\hline \multicolumn{4}{|l|}{ Teudis } \\
\hline Teudis sp. & - & - & 6 \\
\hline T. rubromaculatus & 8 & 1 & - \\
\hline \multicolumn{4}{|l|}{ Xiruana } \\
\hline X. hirsuta & 8 & 5 & - \\
\hline \multicolumn{4}{|l|}{ THOMISIDAE } \\
\hline \multicolumn{4}{|l|}{ Epicadus } \\
\hline Epicadus sp. & 1 & - & 1 \\
\hline \multicolumn{4}{|l|}{ Misumena } \\
\hline Misumena spp. & 2 & 1 & 4 \\
\hline \multicolumn{4}{|l|}{ Misumenoides } \\
\hline Misumenoides sp. & - & 2 & - \\
\hline \multicolumn{4}{|l|}{ Misumenops } \\
\hline Misumenops spp & 40 & 14 & 16 \\
\hline \multicolumn{4}{|l|}{ Sidymella } \\
\hline S. lucida & 11 & 3 & 3 \\
\hline \multicolumn{4}{|l|}{ Strophius } \\
\hline Strophius sp. & - & 2 & - \\
\hline \multicolumn{4}{|l|}{ Synaemops } \\
\hline S. nigridorsi & - & 3 & 1 \\
\hline \multicolumn{4}{|l|}{ Synema } \\
\hline Synema sp. & 1 & - & - \\
\hline \multicolumn{4}{|l|}{ Tmarus } \\
\hline Tmarus sp. & 48 & 16 & 57 \\
\hline \multicolumn{4}{|l|}{ SALTICIDAE } \\
\hline \multicolumn{4}{|l|}{ Lyssomanes } \\
\hline Lyssomanes sp. & 12 & 5 & 7 \\
\hline \multicolumn{4}{|l|}{ Synemosina } \\
\hline Synemosina sp. & 1 & - & - \\
\hline \multicolumn{4}{|l|}{ Zygoballus } \\
\hline Zygoballus sp. & 1 & - & - \\
\hline \multicolumn{4}{|l|}{ TETRAGNATHIDAE } \\
\hline \multicolumn{4}{|l|}{ Chrysometa } \\
\hline Chrysometa sp. & - & 2 & - \\
\hline
\end{tabular}

Tabela 2 - (continuação) 


\begin{tabular}{|c|c|c|c|}
\hline Leucauge & & & \\
\hline Leucauge sp. & 15 & 4 & 20 \\
\hline Nephila & & & 31 \\
\hline N. clavipes & 21 & 22 & 17 \\
\hline Tetragnatha & & & \\
\hline Tetragnatha sp. & 25 & 5 & 7 \\
\hline MIMETIDAE & & & 1 \\
\hline Ero & & & \\
\hline E. lata & 8 & - & 1 \\
\hline Gelanor & & & \\
\hline Gelanorsp. & - & 8 & \\
\hline Mimetus & & & \\
\hline Mimetus sp. & 1 & 2 & \\
\hline CORINNIDAE & & & \\
\hline Castianeira & & & \\
\hline Castianeira sp. & 2 & 1 & \\
\hline Trachelas & & & \\
\hline Trachelas sp. & 3 & 2 & \\
\hline ULOBORIDAE & & & \\
\hline Miagrammopes & & & \\
\hline Miagrammopes sp. & 1 & - & \\
\hline Uloborus & & & \\
\hline Uloborus sp. & 4 & 5 & \\
\hline OXYOPIDAE & & & \\
\hline Oxyopes & & & \\
\hline Oxyopes sp. & - & & \\
\hline Peucetia & & & \\
\hline Peucetia sp. & - & & \\
\hline DEINOPIDAE & & & \\
\hline Deinopis & & & \\
\hline Deinopis sp. & 2 & - & \\
\hline SENOCULIDAE & & & \\
\hline Senoculus & & & \\
\hline Senoculus sp. & 3 & & \\
\hline HERSILIIDAE & & & \\
\hline Tama & & & \\
\hline Tama sp & - & & \\
\hline Tam & & & \\
\hline
\end{tabular}

Tabela 2 - (continuação) 
e, conseqüentemente, afetado a proporção numérica.

Pode-se observar na tab. 1 que a coleta que produziu, individualmente, o maior número de exemplares foi, para todas as localidades, a do inverno do mês de agosto de 1995, indicando que essa estação é a mais apropriada para detectar a diversidade da araneofauna arborícola da região dos morros de Santa Maria.

No quadro da Fig. 3, pode-se analisar a variação da distribuição dos indivíduos jovens e adultos e a proporção de machos e fêmeas ao longo do período de amostragem.

No Perau Velho, a coleta que produziu o maior número de adultos foi feita em março de 1996 (início do outono); já na de maio de 96 (fim do outono) foram obtidos menos indivíduos sexualmente maduros do que em qualquer das coletas do ano anterior, independente da estação. Em São Marcos, as coletas de inverno e primavera (respectivamente agosto e novembro de 1995) produziram praticamente o mesmo número de formas adultas, resultado que se repetiu no outono de 96 ; nesta localidade as coletas de verão (janeiro 95/96) foram as menos produtivas. Na Cidade dos Meninos, o maior número de adultos ocorreu no verão de 96 (ultrapassando largamente $o$ que fora obtido no verão anterior), seguindo-se o outono $e$ inverno de $95 \mathrm{com}$ números muito próximos. A coleta da primavera de 95 foi a que produziu o menor número de indivíduos sexualmente maduros.

A variabilidade observada nos três pontos de coleta sugere que não há uma estação preferencial para a presença de formas adultas de aranhas, quando analisadas em seu conjunto. Talvez, uma análise de cada taxon, em cada estação, demonstre algum padrão de ocorrência das formas adultas.

Quanto à proporção entre formas jovens e adultas, os dados obtidos mostram que a coleta de março de 96 (Outono I) no Perau Velho foi 


\begin{tabular}{cccccccccccccccccc}
\hline \multicolumn{1}{c}{ Perau Velho } & \multicolumn{1}{c}{ São Marcos } & \multicolumn{1}{c}{ C. dos Meninos } \\
\hline & Pri & Ver & Out I & Out II & Inv & Pri & Ver I & Ver II & Out I & Out II & Inv & Pri & Ver I & Ver II & Out & Inv \\
no.m & 18 & 19 & 36 & 11 & 28 & 14 & 5 & 13 & 6 & 15 & 27 & 14 & 15 & 32 & 14 & 29 \\
no.f. & 38 & 20 & 54 & 16 & 16 & 31 & 16 & 18 & 26 & 29 & 17 & 17 & 33 & 38 & 43 & 25 \\
Adult & 56 & 39 & 90 & 27 & 44 & 45 & 21 & 31 & 32 & 44 & 41 & 31 & 48 & 70 & 61 & 54 \\
no. j. & 126 & 61 & 57 & 98 & 196 & 103 & 35 & 72 & 108 & 167 & 221 & 61 & 50 & 70 & 70 & 155 \\
Total & 182 & 100 & 147 & 125 & 240 & 148 & 56 & 103 & 140 & 211 & 259 & 92 & 98 & 140 & 131 & 209 \\
\hline
\end{tabular}

Figura 3: Estrutura populacional, por estação, em cada ponto de coleta

$$
\begin{aligned}
& \text { Legenda: } n \text { ํ. m. (número de machos) } \\
& \text { no. f. (número de fêmeas) } \\
& \text { adult (número de adultos) } \\
& \text { no. j. (número de jovens) }
\end{aligned}
$$


a única, em toda a campanha, em que o número de adultos predominou sobre o de jovens. Todas as outras coletas feitas neste local mostram forte predomínio de jovens e imaturos, independente da estação; o mesmo pode ser constatado em São Marcos. Na Cidade dos Meninos, houve equilíbrio entre formas adultas e jovens no verão e outono, predominando os jovens na primavera e inverno ( Fig. 4 )

O maior número de jovens ocorre sempre no inverno (Figs. 3 e 4), o que explica o maior número de espécimes nesta estação, observado na Tab. 1. Formas adultas de alguns taxa, inclusive, não chegaram a ser encontradas, como é o caso de representantes da família Pisauridae, cuja ausência de indivíduos maduros nas copas das árvores e arvoretas indicaria, segundo BUSS (1993), uma possível troca de habitat.

De maneira geral, pode-se dizer que a freqüência das formas adultas registrada na presente pesquisa é diferente daquela constatada por BUSS (1993), que menciona número de formas adultas quase igual ao de jovens no verão e outono, aumentando na primavera e verão.

Talvez, essa diferença de resultados esteja associada a pequenas variações fisiográficas nos locais estudados (vide Área de Estudo) ou, ainda, à variação na estrutura populacional de cada família, gênero ou espécie, cuja abundância é algo variável nos três locais amostrados (Tab. 1).

Quanto à proporção sexual, nos três pontos de coleta os machos predominaram sobre as fêmeas nas coletas de inverno (agosto de 1995), ainda que por diferenças numericamente pequenas. Nos demais meses houve predomínio das fêmeas (Fig. 3).

O período de maior número de machos (inverno) é, também, o de recrutamento (Figs. 3 e 4); essa coincidência pode estar associada à biologia das aranhas presentes na região estudada.

A literatura básica sobre aranhas (PRESTON-MAPHAM,1984) menciona o fato de algumas fêmeas predarem os machos após a cópula. 


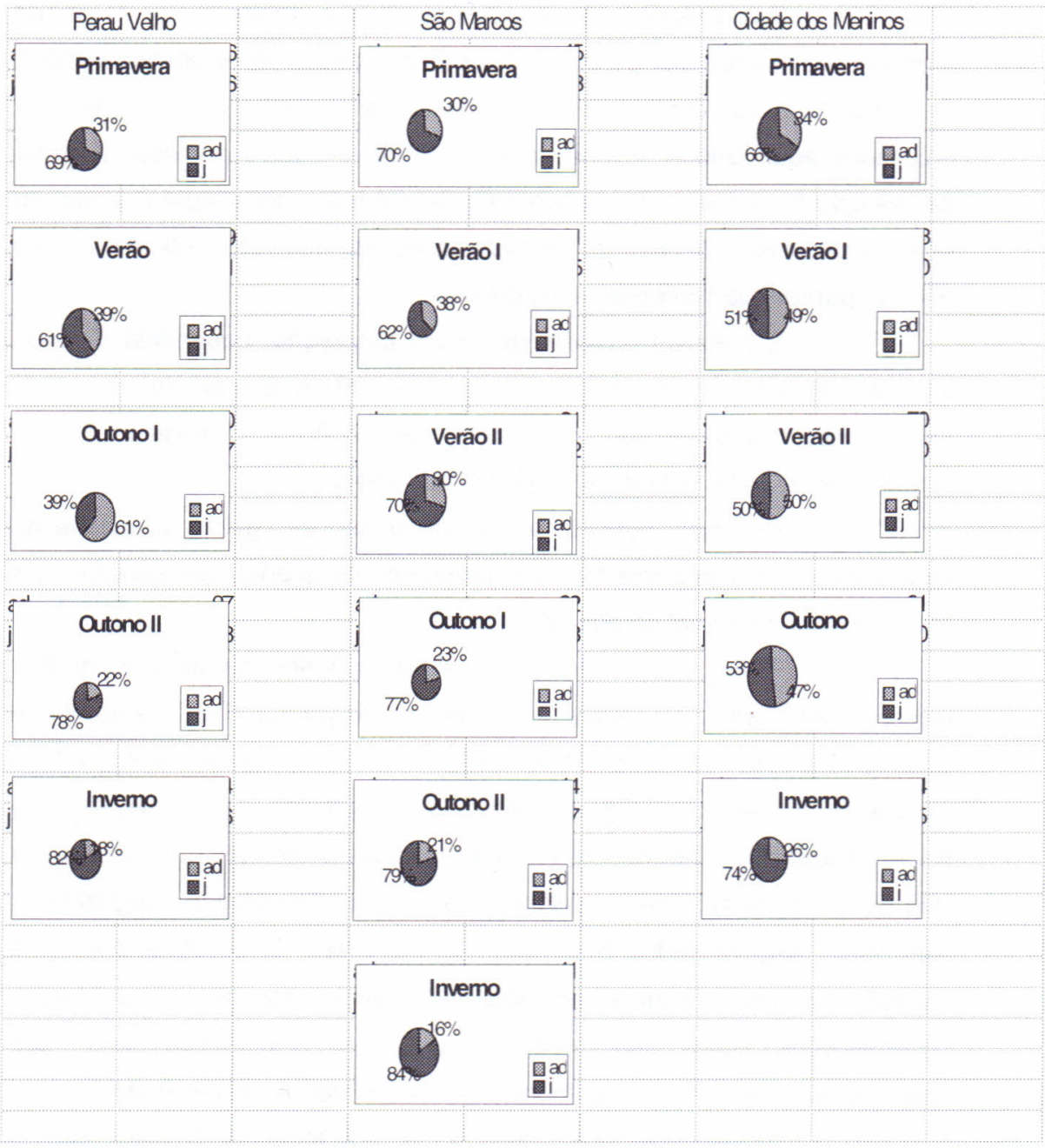

Figura 4 - Números de adultos e jovens, por estação, em cada ponto de coleta

A literatura indica também que o período para eclosão dos ovos é de 20 a 28 dias após a postura (BÜCHERL, 1972). 
Se a época de acasalamento for, também, a de maior predação de machos por parte das fêmeas e se, na área estudada, a época de acasalamento estiver sobrepondo-se ao período de eclosão, os resultados aqui obtidos devem estar sendo influenciados por esse aspecto da biologia das aranhas. Seria esperado também que após esse período, ou seja, na primavera, ocorresse um decréscimo dos machos, o que se verifica (Fig. 3), parecendo confirmar tal hipótese.

É possível também que essa proporção, observada para as aranhas coletadas como um todo, esteja associada a apenas alguns grupos taxonômicos, hipótese que só poderá ser confirmada mediante novos estudos, enfocando cada família, gênero ou espécie.

Um outro aspecto a considerar são as ligeiras variações de resultados obtidos nos três locais separadamente quando comparados aos resultados da área total de estudo.

A Fig. 2a mostra que no Perau Velho as famílias melhor representadas são Araneidae, Theridiidae, Anyphaenidae, Salticidae e Thomisidae, o que coincide com o resultado do quadro geral, na Fig. 2d. Já na Cidade dos Meninos (Fig. 2b) há um predomínio de Theridiidae, seguido por Anyphaenidae, Thomisidae, Araneidae e Tetragnathidae. Em São Marcos (Fig. 2c), ocorrem mais indivíduos da família Theridiidae, seguindo-se Araneidae, Anyphaenidae,Thomisidae e Salticidae. É provável que esta variação, tal como aquela mencionada anteriormente para a proporção adultos/jovens, esteja relacionada às diferenças fisiográficas, ainda que aparentemente pequenas, dos locais estudados (vide Área Estudada).

Observa-se, ainda, que o local onde foi obtido o maior número de exemplares foi São Marcos, seguido de Perau Velho e Cidade dos Meninos. É neste último ponto, entretanto, que se observou a maior diversidade, pois todas as famílias estão aí representadas (Fig. 2b), o que não ocorreu nos dois outros pontos (Figs. 2a e 2c).

Os dados apresentados nesta pesquisa não tem caráter estatístico. Podem ter ocorrido tendenciamentos em certas amostragens, 
conforme já mencionado. Há necessidade de efetuar-se coletas mensais para se ter segurança sobre o comportamento da fauna de aranhas nos meses de cada estação e de um período maior de amostragem, a fim de conhecer-se o efeito de variáveis meteorológicas e outras que não foi possível detectar. Possivelmente, a estrutura populacional de certos taxa (gênero, espécie), principalmente daqueles mais abundantes, deve ter influenciado alguns dados obtidos no presente trabalho. Deve-se levar em conta também que os locais estudados estão sujeitos a forte ação antrópica: em duas ocasiões, no verão de 95 e 96 no Perau Velho e em novembro de 95 na Cidade dos Meninos houve grande desbaste da vegetação ao longo da trilha de coleta, cujo efeito não foi possível avaliar a não ser em um caso: a quase ausência de Nephila clavipes no Perau Velho em março de 96. Em anos anteriores, essa aranha havia sido abundante neste local e esperavase encontrar um grande número de exemplares da mesma, haja visto a ocorrência de muitos jovens na coleta da primavera precedente.

\section{CONSIDERAÇÕES FINAIS}

Os dados obtidos na presente pesquisa permitem constatar algumas informações acerca da diversidade e abundância das famílias de aranhas arborícolas da região de Santa Maria, ainda que de forma preliminar.

As famílias Araneidae, Theridiidae, Anyphaenidae, Salticidae e Thomisidae são, nessa ordem, as melhor representadas numericamente.

A estação mais apropriada para a captura de aranhas é o inverno, no mês de agosto; o grande número de espécimes coletados está associado à época de recrutamento.

Não foi observada uma sazonalidade marcante para a maturação sexual. Entretanto, durante o inverno, o número de machos parece superar, ainda que por pequena diferença numérica, o de fêmeas. 
As pequenas variações de resultados quanto à abundância das famílias melhor representadas na região e as diferenças de dados quanto ao período de maior ocorrência de adultos, verificadas nos três pontos de coleta, podem estar associadas a pequenas variações fisiográficas das localidades estudadas ou, ainda, a variações na estrutura populacional de cada taxon. Novos estudos na área pesquisada, direcionados particularmente para certas famílias, gêneros ou espécies, poderão auxiliar a esclarecer estas discrepâncias, bem como corroborar os dados aqui obtidos.

\section{AGRADECIMENTOS}

A Arno Antonio Lise, Regina Gressler Buss e Augusto Braul Jr. (PUC/RS),e Antonio D. Brescovit (IBSP), pelo auxílio na identificação das aranhas, especialmente das espécies de Thomisidae, Araneidae e Anyphaenidae. A Adelino Alvarez Filho e Roseli L. C. Bortoluzzi (UFSM) pela identificação das espécies vegetais dos locais de coleta. À Família Dalben, de São Marcos, e à Direção da Cidade dos Meninos, pela permissão de acesso a dois dos pontos de coleta. A Ricardo Alexandre Gressler Garcia, de Cachoeira do Sul, pelo auxílio na confecção de alguns dos gráficos. 


\section{REFERÊNCIAS BIBLIOGRÁFICAS}

BEARZI, R. C.; POLTRONIERI, V. C.; LONGHI, S. J. Estrutura fitossociológica do Morro das Três Marias, RS. In: CONGRESSO FLORESTAL ESTADUAL, 7, 1992, Nova Prata. Anais ... Nova Prata, 1992, p. 376-379.

BONALDO, A. B.; BRESCOVIT, A. D. As aranhas do gênero Cheiracanthium C.L. Koch,1839, na Região Neotropical. Rvta. bras. Ent., São Paulo,v. 36, n. 4, p. 731-740. Dez.1992.

BRESCOVIT, A. D. Revisão de Anyphaeninae Bertkau a nível de gêneros na região Neotropical (Araneae, Anyphaeninae). Rvta. bras.Zool., Curitiba, v.13, supl. 1, p. 1-187, dez., 1986.

Revisão do grupo prospera do gênero Aysha Keyserling, 1891, na Região Neotropical (Araneae, Anyphaenidae). Iheringia, sér. Zoologia, Porto Alegre, n.72, p. 23 - 104. Ago.1992a.

Revisão das aranhas neoptropicais do gênero Anyphaenoides Berland, 1913 (Araneae, Anyphaenidae). Rvta. bras. Ent. v. 36 , n. 4, p. 741-754. Dez. 1992 b.

BÜCHERL, W. Aranhas do Rio Grande do Sul. Porto Alegre, Reunião da SBPC, IV, 1952.

1972,158p.

Invertebrados: as aranhas. São Paulo, EDART,

BUSS, R. G. Araneofauna arborícola da região de Cachoeira do Sul, Rio Grande do Sul. Cachoeira do Sul, RS, Fundação Educacional do Vale do Jacuí / Universidade Federal de Santa Maria, 79 p.,1993. (Monografia de Especialização)

KASTON, B. J.; KASTON, E. The spiders. lowa, Brown, 1950. 220 p.

LEVI, H. W.; LEVI, L. R. The genera of the spider family Theridiidae. Bull. Mus. comp. Zool. Harv., Cambridge, v. 127, n. 1, p. 1 - 71, 1962.

LEVI, H. W.; LEVI, L. R. Spiders and their kin. New York, Golden Press, $1990,160 \mathrm{p}$.

LISE, A. A.; BRAUL, Jr., A. Acacesia graciosa, a new species from the Neotropical Region. (Araneae, Araneidae). Biociências, Porto Alegre, v. 3, n. 2, p. 179-184, dez. 1995. 
MACHADO, P. F. S.; LONGHI, S. J. Aspectos florísticos e fitossociológicos do "Morro do Elefante", Santa Maria, RS. Rev. Centro de Ciências Rurais, Santa Maria, v. 20, n. 3 e 4, p. 261-280. 1990.

MELLO-LEITÃO, C. de. Catálogo das aranhas do Rio Grande do Sul. Arq. Mus. Nacional, Rio de Janeiro, v. 37, p. 150-244. 1943.

PEREIRA, P. R. B.; GARCIA NETTO, L. R.; BORIN, C. J. A.; BARROSSARTORI, M. G. Contribuição à geografia física do Município de Santa Maria: Unidades de Paisagem. Geografia - Ensino e Pesquisa, Santa Maria, v. 3, p. 37-68.1989.

PIKELIN, B. S. G.; SCHIAPELLI, R. D. Llave para la determinación de familias de arañas argentinas. Physis, Buenos Aires, v. 24, n. 67, p. 4364.1963

PRESTON-MAPHAM, R.; PRESTON-MAPHAM, K. Spiders of the world. New York, Blandford Press ,1984, $191 \mathrm{p}$. 